\title{
Vazão de água em relação ao posicionamento de bebedouros do tipo nipple para coelhos
}

\section{Water flow in relation to the positioning of nipple drinkers for rabbits}

\section{Flujo de agua en relación con el posicionamiento de los bebederos de pezón para conejos}

\author{
Lucas Eduardo Silva Pereira ${ }^{1}$, João Soares Gomes Filho ${ }^{2}$, Carlos Augusto Rocha de \\ Moraes Rego ${ }^{3}$, Thaís Brito Freire ${ }^{4}$, Camila Moraes Silva ${ }^{5}$ \\ ${ }^{1}$ Bacharel em Zootecnia, Universidade Estadual do Maranhão, São Luís, MA. \\ E-mail: lucas.eduardoztc@gmail.com \\ ${ }^{2}$ Professor Doutor do Departamento de Zootecnia Universidade Estadual do Maranhão São Luís, MA \\ E-mail: joaosoares.filho@ hotmail \\ ${ }^{3}$ Doutorando em Agronomia, Universidade Estadual do Oeste Paraná, Marechal Cândido Rondon, PR. \\ E-mail: cassielcarlos@ hotmail.com. \\ ${ }^{4}$ Pós-graduanda em aquicultura, Universidade Federal de Santa Catarina, Santa Catarina, SC. \\ E-mail: thabritof@gmail.com \\ ${ }^{5}$ Doutoranda em defesa sanitária animal, Universidade Estadual do Maranhão, São Luís, MA. \\ E-mail: camilamoraes.medvet@outlook.com
}

\begin{abstract}
RESUMO
O presente estudo tem como objetivo verificar a vazão da água em relação à posição de bebedouros do tipo Nipple, verticais e inclinados, empregados na dessedentação de coelhos. Este trabalho foi realizado no setor de Cunicultura do Departamento de Zootecnia da Universidade Estadual do Maranhão (UEMA), onde são criados animais mestiços com densidade de 1 unidade animal por gaiola suspensa. Foram avaliadas duas posições em delineamento inteiramente casualizado com dez repetições. Foram coletados volumes de água durante 10 dias de maneira asséptica com coleta de 20 amostras por dia dos bebedouros do tipo nipple. Os dados obtidos foram submetidos à análise de variância pelo teste $\mathrm{F}(\mathrm{p}<0,05)$ e as médias comparadas pelo teste de Tukey $(\mathrm{p}<0,05)$. Notou-se que não houve diferenças significativas quanto à posição dos bebedouros disponíveis aos coelhos, com médias de 3,38 $\mathrm{mL} / \mathrm{seg}$ (Vertical) e 3,02 mL/seg (Inclinado). A vazão de água do bebedouro do tipo nipple não sofre interferência de sua posição, vertical ou inclinada, embora o posicionamento inclinado resultou em uma média numericamente menor.
\end{abstract}

Palavras-chave: coelhos, dessedentação, inclinado, relato, vertical

\begin{abstract}
The present study aims to verify the water flow in relation to the position of vertical and inclined Nipple drinking fountains, used in the watering of rabbits. This work was carried out in the sector of Cuniculture of the Animal Science Department of the State University of Maranhão (UEMA), were crossbred animals are produced, with density of 1 animal units per suspended cage. Two positions were evaluated on the completely randomized design with ten replications. Volumes of water were collected for 10 days aseptically with the collection of 20 samples per day from Nipple drinkers. The data obtained were subjected to analysis of variance by the $F$ test $(p<0.05)$ and the means compared by the Tukey test $(p<0.05)$. It was
\end{abstract}


noted that there were no significant differences as to the position of drinking fountains available to rabbits, with averages of $3.38 \mathrm{~mL} / \mathrm{sec}$ (Vertical) and $3.02 \mathrm{~mL} / \mathrm{sec}$ (Inclined). The water flow of the Nipple drinker is not interfered in relation to the vertical or inclined position, although the inclined positioning resulted in a numerically lower average.

Keywords: desedentation, inclined, rabbits, report, vertical,

\section{RESUMEN}

Resumen: El presente estudio tiene como objetivo verificar el flujo de agua en relación con la posición de los bebederos verticales e inclinados, utilizados en el riego de conejos. En este trabajo se realizó el estudio en el sector de Cunicultura del Departamento de Zootecnia de la Universidad Estatal de Maranhão (UEMA), en el que se crían animales cruzados, con densidad de 1 unidad animal por jaula suspendida. Se evaluaron dos posiciones en el diseño completamente al azar con diez repeticiones. Se recogieron volúmenes de agua durante 10 días de manera aséptica con la recolección de 20 muestras por día de bebedores de pezón. Los datos obtenidos fueron sometidos a análisis de varianza por la prueba $\mathrm{F}(\mathrm{p}<0.05)$ y las medias comparadas por la prueba de Tukey $(\mathrm{p}<0.05)$. Se observó que no había diferencias significativas en cuanto a la posición de los bebederos disponibles para los conejos, con promedios de $3.38 \mathrm{~mL} / \mathrm{seg}$ (Vertical) y $3.02 \mathrm{~mL} / \mathrm{seg}$ (Inclinado). El flujo de agua del bebedero de pezón no se interfiere en relación con la posición vertical o inclinada, aun que la posición inclinada resultó en un promedio numéricamente más bajo.

Palabras clave: conejos, desedentación, inclinado, reporte, vertical

\section{Introdução}

A produção de alimentos, vegetais e animais, é dependente do emprego da água, a qual é fundamental para existência de vida no planeta. O manejo da água é essencial para uma produção equilibrada, pois não há produção sem água de quantidade e qualidade, do mesmo modo que não há um substituto para água (Palhares, 2016). Segundo WWAP (2019), a agricultura e pecuária são os principais consumidores de água, representando $69 \%$ das extrações anuais a nível global. Ainda segundo WWAP espera-se um aumento na demanda global por água até 2050, na ordem de 20 a $30 \%$, onde o uso para agricultura e pecuária em relação ao uso total deverá reduzir em comparação a outros setores produtivos, devido principalmente ao emprego de manejos racionais desse recurso.

A importância da água para a criação animal está relacionada à grande variedade de funções que desempenha no organismo e a magnitude de seus efeitos, considerando assim essencial para os animais. $O$ fornecimento de água nas fazendas produtivas é realizado à vontade, enquanto o consumo pelos animais está relacionado a fatores como espécie, temperatura, atividade física entre outros.

A criação de coelhos (Oryctolagus cuniculus) ou cunicultura é o ramo da zootecnia que tem como objetivo a produção de carne e subprodutos, sendo 
desenvolvida por diversos países, pois estes animais conseguem, em pouco tempo, produzir consideráveis quantidades de proteína de alto valor biológico, além de ser um nicho de mercado em desenvolvimento. $\mathrm{O}$ consumo de água de um coelho é o dobro do peso de alimento que consome, podendo atingir em machos reprodutores 0,5 a 1 litros/cabeça/dia (Pinheiro e Mourão, 2006) e em fêmeas com seis láparos pode chegar a até 2 litros/cabeça/dia (Andriguetto,1986), portanto o fornecimento deve ser realizado de forma a suprir a necessidade desses animais.

O fornecimento de água aos animais normalmente é realizado por bebedouros instalados nos locais de criação e existem vários modelos, entretanto o mais recomendado é o tipo nipple, devido à sua praticidade e funcionalidade, permitindo o acesso à água em quantidade adequada, sem que haja desperdício. Além disso, o investimento para automatizar o sistema é baixo e o criador economiza tempo. Por isso, esse sistema é amplamente utilizado na cunicultura industrial (Carvalho, 2009; Rios et al., 2011).

Baseado no exposto e nas poucas informações em nosso meio sobre o assunto, ou seja, a temática do fornecimento de água para produção de coelhos, o presente estudo tem como objetivo verificar a vazão da água em relação à posição de bebedouros do tipo nipple, verticais ou inclinados, empregados na dessedentação de coelhos.

\section{Material e Métodos}

$\mathrm{O}$ experimento foi realizado no setor de Cunicultura do Departamento de Zootecnia da Universidade Estadual do Maranhão (UEMA), campus de São Luís. O clima local, segundo a classificação de Köppen, é do tipo Aw, ou seja, equatorial quente e úmido, com estação chuvosa de janeiro a junho (média de $2010 \mathrm{~mm}$ ) e estação seca de julho a dezembro (média de $180 \mathrm{~mm}$ ), com temperatura média anual de $26,1{ }^{\circ} \mathrm{C}$, com variações de $30,4{ }^{\circ} \mathrm{C}$ e $23,3^{\circ} \mathrm{C}$ e a umidade relativa média é de 88\% (INMET, 2009; CPTEC 2010).

$\mathrm{O}$ delineamento experimental empregado foi o inteiramente casualizado, com dois tratamentos e dez repetições. Os tratamentos empregados foram duas diferentes posições dos bebedouros do tipo nipple, que foram os posicionamentos vertical e inclinado.

Foram realizadas coletas durante 10 dias, de maneira asséptica, pressionando-se a válvula dos bebedouros com espátula fazendo pressão máxima, produzindo um fluxo de água por 1 minuto, diretamente para o copo receptor. Essa água coletada era transportada para uma proveta graduada, sendo estas 
medidas numeradas e divididas segundo sua posição para identificação.

Os dados obtidos foram submetidos à análise de variância pelo teste $\mathrm{F}(\mathrm{p}<0,05)$ e as médias comparadas pelo teste de Tukey $(\mathrm{p}<0,05)$. As análises estatísticas foram realizadas com o auxílio do programa estatístico $\mathrm{R}$ ( $\mathrm{R}$ DEVELOPMENT CORE TEAM, 2016).

\section{Relato de caso}

No setor de Cunicultura do Departamento de Zootecnia da Universidade Estadual do Maranhão UEMA, a utilização de bebedouros tipo nipple se dá por sua praticidade e funcionalidade, quando comparado com outros modelo. Além disso, permite o acesso à água em quantidade e qualidade adequada para os coelhos criado no local, sendo raças mestiças de Nova Zelândia Branco x Chinchila e Nova Zelândia Branco x Nova Zelândia Vermelho, apresentando ao todo 25 animais, sendo 1 unidade animal por gaiola suspensa

$\mathrm{O}$ fato da forma como os bicos dos bebedouros estava disposto e a forma como os coelhos dessedentavam-se chamou a atenção de orientador e aluno, que com base nesse fato desencadearam observação e apuração, da influência da posição dos bebedouros na produção.

\section{Resultado e Discussão}

Para os tratamentos empregados não foram observados valores discrepantes em relação as medidas de separatrizes (Figura 1A). No presente estudo não foram encontradas diferença de vazão relacionado à posição dos bebedouros do tipo nipple (Figura 1B) sendo apresentadas médias de $3,38 \mathrm{~mL} / \mathrm{seg}$ para a posição vertical e $3,02 \mathrm{~mL} / \mathrm{seg}$ para a inclinado, com médias não diferindo pelo erro padrão e pelo teste de Tukey $(\mathrm{p}<0,05)$. Embora não se tenha observado diferença entre as posições dos bebedouros pode-se classificá-los como de alta vazão (>2,3 $\mathrm{mL} / \mathrm{seg}$ ), diante disso apresentam maior desempenho quando comparados a bebedouros de baixa vazão $(0,4 \mathrm{~mL} / \mathrm{seg})$ em criações com altas densidades (Macari, 1996). Segundo Rios (2011) o emprego de bebedouro automatizado é o mais recomendado, pois este tipo de bebedouro possui uma maior vazão, o que resulta em melhor desempenho para criações em alta densidade. 

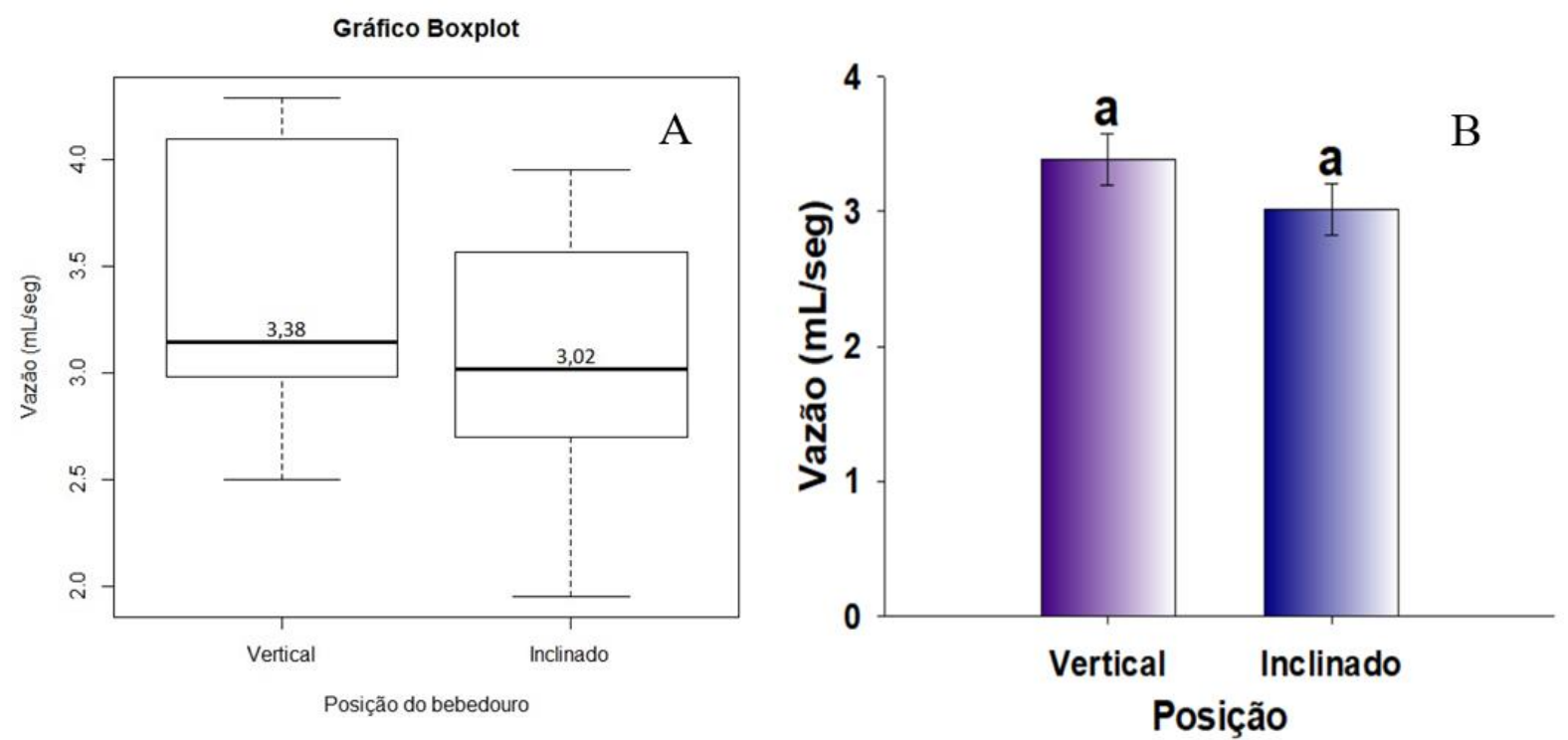

Figura 1. Quartis (A) e médias (B) dos diferentes posicionamentos dos bebedouros.

Observou-se durante esse estudo que devem ser feitas verificações periódicas na distribuição de água dos bebedouros do tipo nipple, uma vez que com o tempo eles podem apresentar problemas quanto à vazão, devido ao entupimento dos mesmos.

Verificou-se também que os bebedouros automatizados são práticos, funcionais e permitem o acesso à água, em quantidade e qualidade adequadas, se comparado com outro modelo, como o tipo taça.

\section{Conclusões}

A vazão de água do bebedouro do tipo nipple não sofre interferência da posição, vertical ou inclinada, embora o posicionamento inclinado tenha resultado em uma média numericamente menor.

A verificação acerca das necessidades do uso consciente da água, bem como da difusão deste mecanismo a outras criações, denotam a necessidade de mais estudos a respeito desse assunto.

\section{Referências Bibliográficas}

ANDRIGUETTO, J. M.; PERLY, L.; MINARDI, J. S.; GEMAEL, A.; FLEMMING, J. S.; SOUZA， G. A. de; BONA FILHO, A. Nutrição animal. 3ed. São Paulo: Nobel, 1986. v2, p. 335352.

CARVAlHO, R. C. Caracterização da produção cunícula nas regiões de Trásos-Montes, Minho e Galiza. 2009. 132 f. Universidade de Tras-os-Montes e Alto Douro, Vila Real, 2009.

INSTITUTO NACIONAL DE METEOROLOGIA (INMET). Normas climatológicas do Brasil 1961-1990. Brasília, DF, 2009, 465p.

MACARI, M. 1996. Água na avicultura industrial. Jaboticabal: FUNEP. 128p.

PALHARES, J. C. P. A experiência brasileira no manejo hídrico das produções animais. In: PALHARES, J. C. P. Produção animal e recursos hídricos. São Carlos: Editora Cubo, 2016. p.11-32 
PINHEIRO, V. M. C.; MOURÃO, J. L. M.

Alimentação do coelho. Série didáctica.

UTAD. Portugal: Vila Real, 2006. p. 81

PROGRAMA MUNDIAL DE

EVALUACIÓN DE LOS RECURSOS

HIIDRICOS DE LA UNESCO (WWAP).

Informe Mundial de las Naciones

Unidas sobre el Desarrollo de los

Recursos Hìdricos 2019: No dejar a nadie atrás. París, UNESCO. 2019. 213p

R DEVELOPMENT CORE TEAM. R: A Language and Environment for Statistical Computing. Vienna, Áustria: The R Foundation for Statistical Computing. 2016.

RIOS, D. M. et al. Manual de cunicultura. 2011. $46 \mathrm{f}$. Universidade do Estado da Bahia, Barreiras, 2011. 